\title{
Effects of the Low Dose Ionizing Radiation (X-ray) on Human Blood Components during Catheterization Process
}

\author{
Khairi MS Abdullah ${ }^{1 *}$, Hussein $\mathrm{HA}^{2}$ and Shareef $\mathrm{ZA}^{3}$ \\ ${ }^{1}$ College of Engineering, University of Duhok, Iraq \\ ${ }^{2}$ College of Medicine, University of Duhok, Iraq \\ ${ }^{3}$ Azadi Teaching Hospital, Iraq
}

*Corresponding author: Khairi MS Abdullah, College of Engineering, University of

Duhok, Iraq, Tel: +9647504581041; Email: Khairi.abdullah@uod.ac

\section{Research Article \\ Volume 3 Issue 4}

Received Date: November 27, 2019

Published Date: December 03, 2019

DOI: $10.23880 /$ macij- 16000150

\section{Abstract}

In a time being, ionizing radiation specifically X-ray is widely used in medicine for diagnosis and therapy. At the same time, such beneficial uses may cause potential hazardous situations for patient and the workers within the Cardiac catheterization laboratory. The present work was conducted to evaluate the changes in some components of blood cells after exposure to radiation during the Cardiac catheterization. A statistical comparative study was performed between pre (as control group) and in the early post-irradiation period of blood components on 33 patients. The mean of RBC counts, in post-irradiation are significantly lower than pre-irradiation values at $4.47 \pm 0.55 \times 10^{12} / \mathrm{L}$ and $4.84 \pm 0.59 \times 10^{12} / \mathrm{L}$ respectively, for plasma hemoglobin $\mathrm{Hb}, 11.95 \pm 1.55 \mathrm{~g} / \mathrm{dl}$ and $12.71 \pm 1,62 \mathrm{~g} / \mathrm{dl}$ respectively and for WBC are $6.87 \pm 1.581$ and 7.58 \pm 1.577 respectively. There are no significant changes observed between pre and post-irradiated levels in RDW and MCV sizes. Even though the quantitative results of the mean percent-hemolysis level is still within the recommended acceptable levels for clinical significance. Further works are required to search other possible effects.

Keywords: X-Ray; Blood Analysis; Ionizing Radiation; Fluoroscopy; Cardiac Catheterization

Abbreviations: IR: Ionizing Radiation; RDW: Red Cell Distribution Width; RBC: Red Blood Cell; MCV: Mean Corpuscular Volume; WBC: White Blood Cell Count; CBP: Complete Blood Picture; Hb: Hemoglobin.

\section{Introduction}

Ionizing radiation (IR) such as gamma and X-ray has an external effect on human body. The energy of IR is high enough to ionize atoms of the medium. As a result of interactions production of free radicals, breaking chemical bonds, cross-linkages between macromolecules, and destructing of molecules in human cells that regulate vital cell operations; in turn it may cause cancer. Fortunately, cells are built to rebuild and repair themselves to certain levels of damage at most clinical radiation exposures involve low doses of $<1 \mathrm{~Gy}$, while higher doses can give rise to cell death [1].

Many studies have been done to find and analyze the evaluation of high and low dose ionizing radiation on hematological parameters. For instance, [2] analyze the blood variations resulting from both irradiation and time 


\section{Medicinal \& Analytical Chemistry International Journal}

for animal rats. They found a significant reduction in WBC, platelet and RBC counts one day after irradiation increases with increasing the dose started from 0.3 to $1 \mathrm{~Gy}$ [3] found the low dose rate on rat and dog effect the hemopoietic failure according to both total absorbed dose and on the dose-rate of multi exposures.

Fluoroscopy is an ideal continuous X-ray devise used in Cardiac catheterization laboratory for medical imaging. It is used often in a lot of different exploring and the operation in steps of diagnoses or treatments of heart diseases patients. It leads the operator by a continuous images (as movie) a beam that passed through the body on a monitor. From monitor the operator follow and direct the movement of a catheter through blood vessels, also place stents or other devices to open the blocked blood vessels [4].

In front of the above advantages of Fluoroscopy, it involves some risks and may cause potential hazardous situations for patient and the worker, as do other X-ray operations. The radiation dose and the time of operation are of the most important controlled parameters that the patient is subjected to, which vary from one patient to another depending on the individual procedure. The equivalency of X-ray irradiation to gamma irradiation is reported in several publications [5,6]. Specifically, their ability to deactivate $\mathrm{T}$ lymphocytes and all blood components such as red cells, white cells, platelets and granulocytes at a same absorbed dose $[7,8]$.

The aim of the present work is to evaluate and analyze the effect of low dose X-ray radiation during the CT operation on some blood components of 33 patients. The considered parameters are Red Blood Cell count (RBC), the amount of hemoglobin ( $\mathrm{Hb})$, Red cell Distribution Width (RDW), Mean Corpuscular Volume (MCV) and White Blood cell Count (WBC).

\section{Material and Methods}

The CT operations have been carried out according the UNSCEAR judgments and regulations at low dose radiation health effect on non-targeted effects. Based on one Cather device (Cardiac catheterization, SN: 1Q1168VR02 (one face) For GE medical system) available in the Azadi general Duhok hospital, data have been collected for 33 heart diseases patients $(11$ male and 22 female) during a period of about 6-month in 2018. The dose rates of X-ray source recorded by Fluoroscopy have been varied from minimum of $(0.78 \mathrm{mGy} / \mathrm{h})$ to maximum of $(6.53 \mathrm{mGy} / \mathrm{h})$ with an average of $(2.08 \mathrm{mGy} / \mathrm{h})$. While the duration time of CT operations are varied from $0.6 \mathrm{~m}$ to $11.2 \mathrm{~m}$, with an average of $2.91 \mathrm{~m}$. Accordingly, the total dose recorded in the monitor are $89 \mathrm{mGy}, 820 \mathrm{mGy}$ and $287 \mathrm{mGy}$ as minimum, maximum and average respectively. These low dose rates are in accordance with the dose rate recommended by the (UNSCEAR 1993).

The laboratory examinations covered a Complete Blood Picture (CBP) to account number of all components in the blood. Hematological parameters (HPs) or (CBC) for all patients are measured by an Automatic hematologic Swelab Alfa basic boule medical a.b analyzer (SN: 11018) at laboratory of Azadi Teaching Hospital. The blood analysis of each patient has been carried out twice by the same laboratory, to ensure the same standard protocol, the first wright before CT while the second in the early post-irradiation period, i.e. within one day of CT operation, for all patients.

\section{Statistical Analysis}

All data were statistically analyzed; the main two parameters used in measurement of area are the mean and standard deviation. The standard deviation is a theoretical expectation of $68.27 \%$ of the measurements of the sample's data that lie within one standard deviation on both sides of the mean under normal distribution.

Statistical analysis was carried out by Social Science Statistics Package (SocSciStatis.com [9]) for P-value and ttest Calculation for two independent groups (pre, as control groups, and post radiation groups) with the aid of EXCEL software for calculations related to normal distribution of the difference between them (post - pre). This software were conducted to investigate the significant difference between the two groups for RBC count, the amount of hemoglobin Hb, RDW, MCV and WBC count. The statistical tests for comparison of numerical variables between groups have been carried out to evaluate the sample distribution normality. The condition of accepting the fitted normal distribution of the sample at a chosen at significance level ( $p$-value $=0.05$ ) is the critical value of P-value not to be greater than 0.409 [10].

\section{Results and Discussion}

Hematological parameters for 33 adult patients (of an average age of 57 years) groups were statistically analyzed and differences between the groups of samples irradiated with mean dose of $287 \mathrm{mGy}$ and the preirradiation control groups of samples are examined statistically. All statistical results for post-irradiation group compared to the pre-irradiation control group of 


\section{Medicinal \& Analytical Chemistry International Journal}

erythrocyte count or RBC, plasma hemoglobin Hb, RDW, $\quad$ MCV and WBC are given in Table 1.

\begin{tabular}{|c|c|c|c|c|c|c|}
\hline Variables & Mean & SD & Min. value & Max. value & t-value & P \\
\hline Pre RBC $\times 10^{12} / \mathrm{L}$ & 4.84 & 0.59 & 3.5 & 5.8 & 2.65 & $0.0051^{*}$ \\
\hline Post RBC $\times 10^{12} / \mathrm{L}$ & 4.47 & 0.55 & 3.43 & 5.6 & & \\
\hline Pre Hb $(\mathrm{g} / \mathrm{dl})$ & 12.71 & 1.62 & 9.7 & 15.2 & 1.95 & $0.0279^{*}$ \\
\hline Post $\mathrm{Hb}(\mathrm{g} / \mathrm{dl})$ & 11.95 & 1.55 & 9 & 15.2 & & \\
\hline Pre RDW & 11.9 & 1.32 & 10.6 & 17.9 & 1.42 & $0.081^{* *}$ \\
\hline Post RDW & 12.38 & 1.41 & 11 & 18.9 & & \\
\hline Pre MCV (fL ) & 81.98 & 6.05 & 61.5 & 93.7 & 0.25 & $0.401^{* *}$ \\
\hline Post MCV (fL ) & 82.37 & 6.24 & 62.2 & 94.5 & & \\
\hline Pre WBC $\times 10^{9} / \mathrm{L}$ & 7.58 & 1.577 & 4.6 & 11.3 & 1.79 & $0.039^{*}$ \\
\hline Post WBC $\times 10^{9} / \mathrm{L}$ & 6.87 & 1.581 & 4 & 10.3 & & \\
\hline
\end{tabular}

*= statistically significant

$* *=$ statistically insignificant

Table 1: Comparison of plasma $\mathrm{Hb}$ and percent hemolysis between the pre- and post-irradiated Samples.

The mean of RBC counts, in post-irradiation are significantly lower than pre-irradiation values $4.47 \pm 0.55$ $\mathrm{x} 10^{12} / \mathrm{L}$ and $4.84 \pm 0.59 \times 10^{12} / \mathrm{L}$ respectively, while for plasma hemoglobin $\mathrm{Hb}$ the post and pre-irradiation are $11.95 \pm 1.55 \mathrm{~g} / \mathrm{dl}$ and $12.71 \pm 1.62 \mathrm{~g} / \mathrm{dl}$ respectively. Also the values for post and pre-irradiated samples for WBC counts are $6.87 \pm 1.581 \times 109 / \mathrm{L}$ and $7.58 \pm 1.577 \times 109 / \mathrm{L}$ respectively. From t-values and P-values the differences between groups of the samples irradiated and the groups of the controlled samples (before irradiation) are statistically significant $(\mathrm{P}<0.05)$. It is obvious that these Hematological parameters of blood were influenced by irradiation dose. It is clear that the $\mathrm{RBC}, \mathrm{Hb}$ and $\mathrm{WBC}$ of blood are decreased by irradiation dose, but still within the normal clinical range. The same effect of irradiation by low $\gamma$ radiation dose and X-ray was documented by some other researchers; according RBCs were damaged so as impairing its value or its normal function by irradiation mainly due to dehydration [11,12].

Our result of $\mathrm{Hb}$ is in contrast to results obtained in the case of gamma irradiation of blood transfusion from blood bank unit by Yousuf, et al. [13] where plasma $\mathrm{Hb}$ increases very little in post-irradiation that was mainly because of the complications accompanied by transfusion not by ionizing radiation. Table 1 shows also the RDW and MCV values pre and post-irradiated samples. The levels of RDW (row 5 and 6) in post and pre-irradiated samples are $12.38 \pm 1.41$ and $11.9 \pm 1.32 \mathrm{mmol} / \mathrm{L}$ respectively, with $\mathrm{P}$-value $=0.081$. Similarly the MCV values, which show negligible increase (row7 and 8) are 82.37 $\pm 6.24 \mathrm{fL}$ and $81.98 \pm 6.05 \mathrm{fL}$ in post and pre-irradiated samples respectively, with $\mathrm{P}=0.401$. It is very clear there are no significant changes observed between pre and postirradiated levels, specifically in MCV level since p-value is very far from 0.05. It is clear the effect of ionizing radiation on both of these parameters is increasing their level by $4 \%$ and $0.5 \%$ for RDW and MCV respectively. This little increase is negligible compare to their normal levels, consequently can be considered as they are not significantly affected by the low level radiation dose.

To highlight the effect of X-ray at the day of irradiation on the parameters undergo a statistically significant decreases between groups regarding the mean, a theoretical expectation of $68.27 \%$ of the measurements of the sample's data that lie within one standard deviation on both sides of the mean under normal distribution are carried out. Figure 1 shows a normal distribution of highly statistically significantly decreases in RBC counts for $68 \% \mathrm{Z}$-value. For this $\mathrm{Z}$-value the decreases for $1 \sigma$ range is shown in Figure 1 and the mean values of the difference (post - pre) sample is $-0.376 \pm 0.340 \times 10^{12} / \mathrm{L}$.

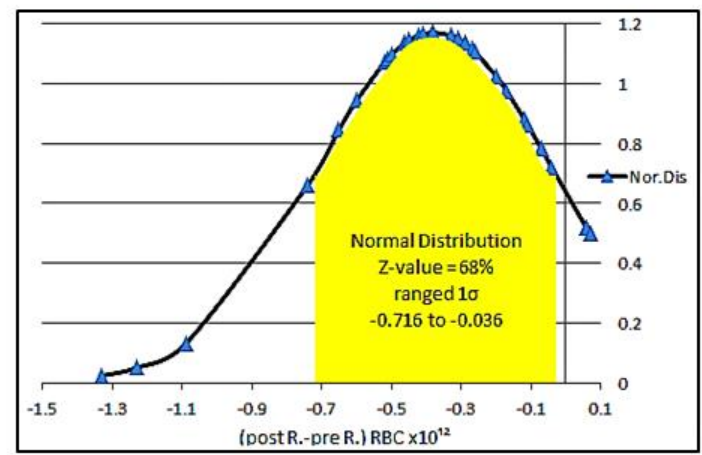

Figure 1: Normal distribution of highly statistically significantly decreases in RBC counts. 


\section{Medicinal \& Analytical Chemistry International Journal}

Similarly, Figure 2 and 3 show the normal distribution of highly statistically significantly decreases in plasma hemoglobin $\mathrm{Hb}$ with the mean of difference $-0.757 \pm$ $0.843 \mathrm{~g} / \mathrm{dL}$ and WBC counts with the mean of difference $0.706 \pm 1.043 \times 10^{9} / \mathrm{L}$.

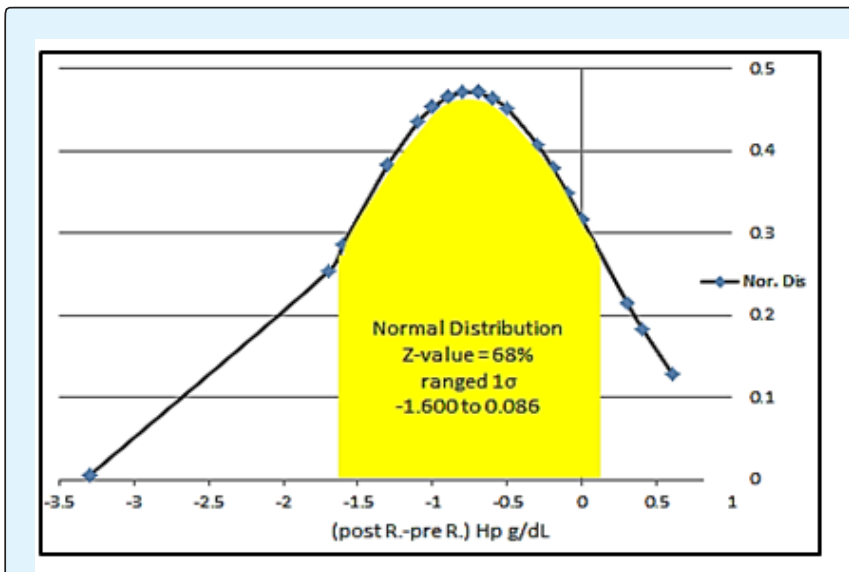

Figure 2: Normal distribution of highly statistically significantly decreases in plasma hemoglobin $\mathrm{Hb}$.

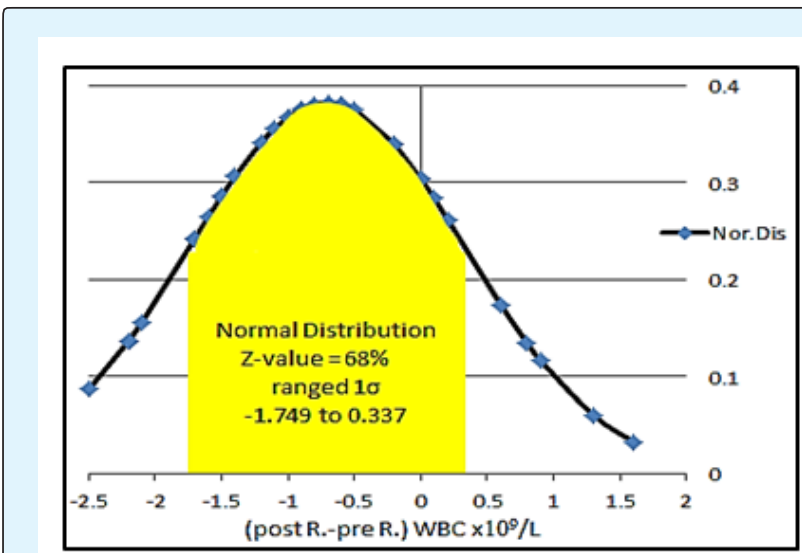

Figure 3: Normal distribution of highly statistically significantly decreases in WBC counts.

\section{Conclusion}

The present study showed that the low level X-ray irradiation, during CT, significantly decreases the erythrocyte (RBC) counts, plasma Hb and WBC counts in blood post-irradiated. The dehydration through the membrane of erythrocytes might be the cause of decreasing RBCs parameters. Even though the quantitative results of the mean percent-hemolysis level is still within the recommended acceptable levels for clinical significance use. Concerning parameters measure the shape, size or volume of red blood cell; there are no noticeable or significant changes in both RDW and MCV shape in pre and post-irradiated samples.

According to these results, it is obvious to assume that irradiated RBC units are clinically safe and of acceptable in CT operation, specifically knowing the capability of blood cell's units to rebuild and repair themselves to certain levels of damage at low dose exposure. This study is not able to conclude that X-ray irradiation was the only cause of such change in blood parameters. Further works are required to search the other possible effects.

\section{References}

1. Kutkov V, Buglova F, McKenna T (2011) Severe deterministic effects of external exposure and intake of radioactive material: basis for emergency response criteria. J Radiol Prot 31(2): 237-253.

2. El-Shanshoury H, El-Shanshoury G, Abaza A (2016) Evaluation of low dose ionizing radiation effect on some blood components in animal model. Journal of Radiation Research and Applied Sciences 9(3): 282293.

3. Fliedner TM, Graessle DH, Meineke V, Feinendegen LE (2012) Hemopoietic response to low dose-rates of ionizing radiation shows stem cell tolerance and adaptation. Dose Response 10(4): 644-663.

4. Caciari T, Capozzella A, Tomei F, Nieto H, Gioffre P, et al. (2011) Professional exposure to ionizing radiations in health workers and white blood cells. Ann Ig 24(6): 465-474.

5. Siiskonen T, Tapiovaara M, Kosunen A, Lehtinen M, Vartiainen E (2007) Monte Carlo simulations of occupational radiation doses in interventional radiology. Br J Radiol 80(954): 460-468.

6. Janatpour K, Denning L, Nelson K, Betlach B, Mackenzie M, et al. (2005) Comparison of X-ray vs. gamma irradiation of CPDA-1 red cells. Vox Sang 89(4): 215-219.

7. Hirayama J, Abe H, Azuma H, Ikeda H (2005) Leakage of potassium from red blood cells following gamma ray irradiation in the presence of dipyridamole, trolox, human plasma or mannitol. Biol Pharm Bull 28(7): 1318-1320. 


\section{Medicinal \& Analytical Chemistry International Journal}

8. Moroff G, Luban NL (1997) The irradiation of blood and blood components to prevent graft-versus host disease: technical issues and guidelines. Transfus Med Rev 11(1): 15-26.

9. Socscistatistics.com.

10. Harvey M, Paige S, Mike P, John P (2014) Graph Pad statistics guide. Graph Pad software Inc prism 6.

11. Badalyan H, Baghdasaryan N, Ohanyan K, Stepanyan M, Kishmiryan A (2016) Dependence of Erythrocyte Shape Parameter on the Low Dose $\gamma$-Irradiation. Armenian Journal of Physics 9(1): 95-99.

12. Suzuki Y, Tateishi N, Cicha I, Shiba M, Muraoka M, et al. (2000) Decreased deformability of the X-ray irradiated red blood cells stored in mannitol-adeninephosphate medium. Clin Hemorheol Microcirc 22(2): 131-141.

13. Yousuf R, Mobin MH, Leong CF (2015) Gamma irradiation and red cell haemolysis: a study at the Universiti Kebangsaan Malaysia Medical Centre. Malaysian J Pathol 37(2): 91-94.

14. National Council on Radiation Protection and Measurements (NCRP) Report 168: Radiation Dose Management for Fluoroscopically Guided Interventional Medical Procedures. 